Please send trade news information and illustrations to Terry Mordecai at the BDJ, 64 Wimpole Street, London W1G 8YS. Trade news is supplied as a service to the reader and does not imply endorsement by the BDJ. Normal and prudent research should be exercised before purchase of use of any product mentioned.

\section{Protection from dentine failure}

Coltene Whaledent is pleased to announce the launch of the Tenax Fibre White.

Coltene Whaledent claims the flexural properties are close to the modulus of dentine, reducing the risk of root fracture.

Coltene Whaledent also claim the Cylindro-conical post design along with the double set of grooves for greater mechanical retention protect against dentine failure.

For more information phone Coltene Whaledent on 0500295454.

Reader response number 52

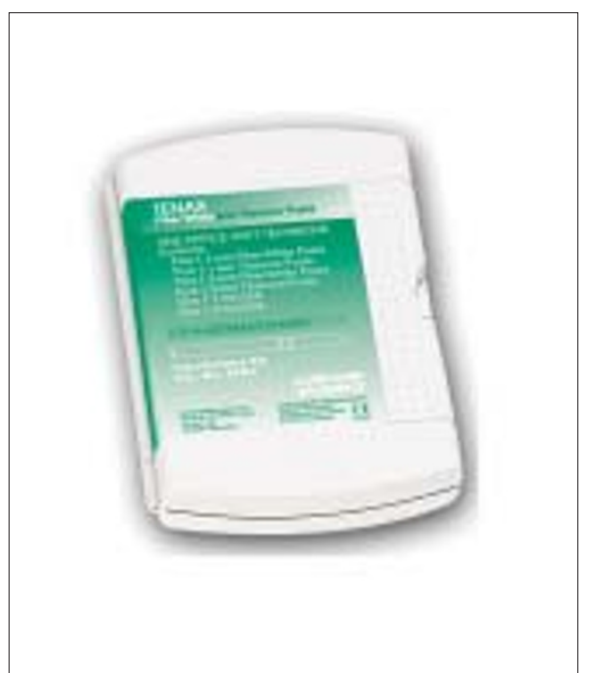

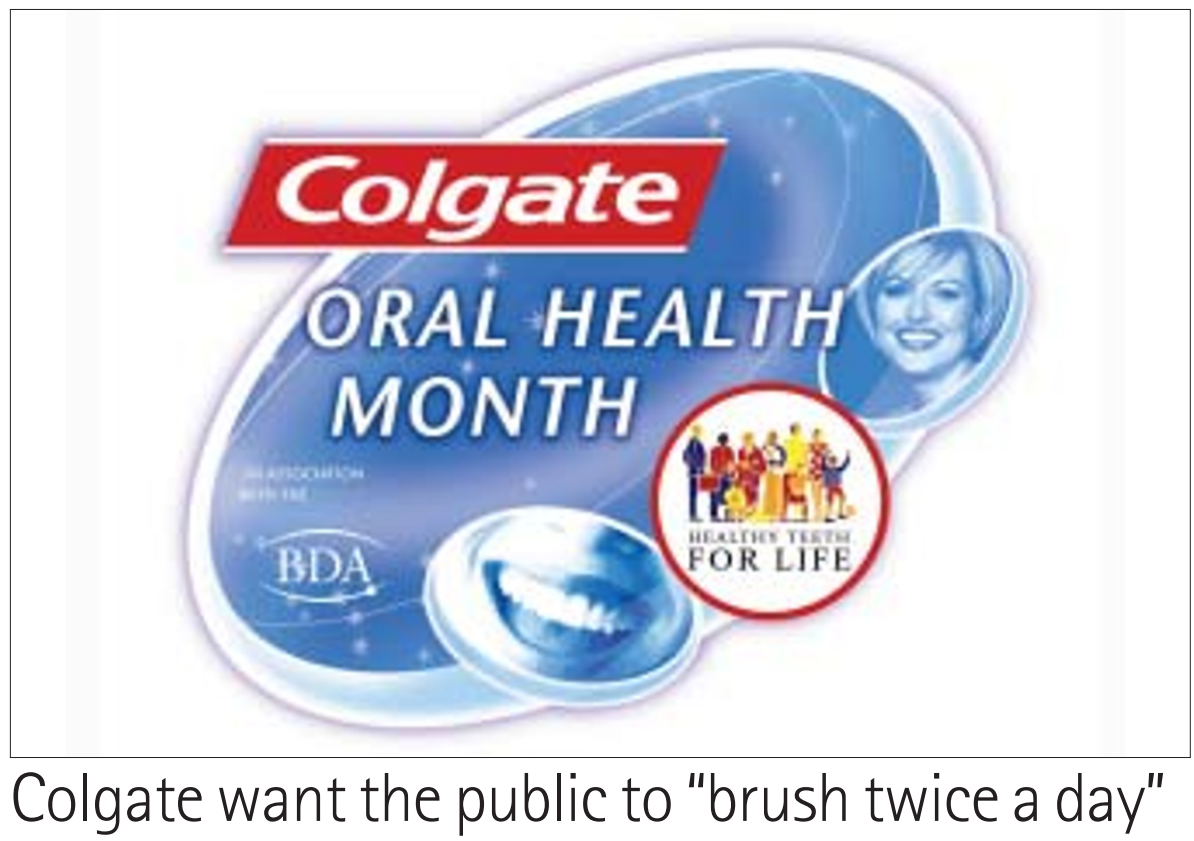

At the BDA conference in Manchester Colgate launched the 2003 Colgate Oral Health Month, in association with the BDA. The message Colgate is promoting this year in the UK is "Brush your teeth twice a day".

Colgate claims data from the 1998 Adult Dental Health Survey shows that the UK population are still not adhering to this fundamental advice. Colgate will also be re-enforcing the dental profession's messages of the importance of using fluoride toothpaste and replacing your toothbrush every 3 months.

As part of Colgate Oral Health Month, Colgate is committed to making a significant contribution to Saving Faces, The Facial Surgery Research Foundation. Saving Faces aims to raise much-needed funds for research into all aspects of the disorders affecting the mouth and face such as cancer, facial deformity, injuries and pain. Practices will be supplied with materials to promote the key messages. For more information phone 01483401 901.

\title{
Improve your patient's comfort during crown removal
}

Mirage Dental is pleased to announce the launch of Wamkey. Mirage claims the classical methods of crown removal, whether manual or mechanical, use traction or rocking but Wamkey is different and therefore saves time and is painless for the patient.

Mirage claims Wamkey has a simple rotation on the handle and will remove a crown in between one and three minutes. The whole crown does not have to be cut because the entry hole is very small. This also saves wear and tear on hand pieces.

Mirage also claims that Wamkey is comfortable for the patients. The three sizes are designed to remove the crown without any shocks, as the pressure of the supporting tooth increases progressively until the crown is removed. There is no pulling or rocking as it dislocates the crown from its support.

For more information about Wamkey phone Mirage on 08451305440. Reader response number 53

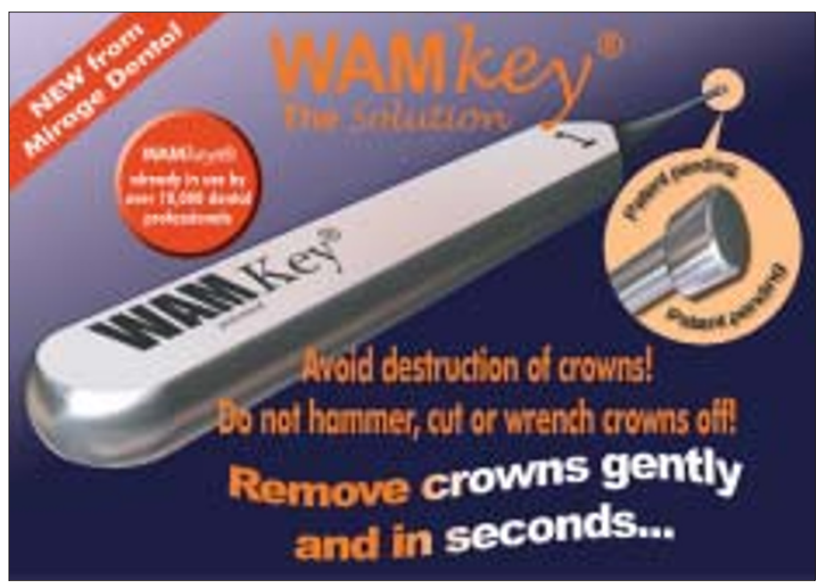

